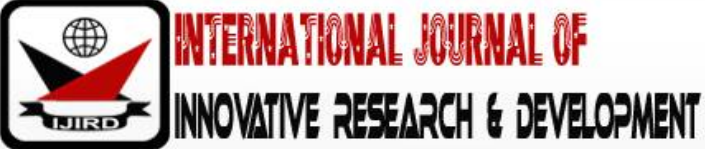

ISSN 2278 - 0211 (Online)

\section{Detection of BCR/ ABL Fusion Gene in Chronic Myeloid Leukaemia Using Reverse Transcriptase Polymerase Chain Reaction}

\begin{tabular}{c} 
Abutu, Phillip Ogah \\
Senior Medical Laboratory Scientist, Department of Medical Laboratory, \\
Paelon Memorial Hospital, Nigeria \\
Osuloye, Oluwaseun Olayemi \\
Lead Medical Laboratory Scientist, Department of Medical Laboratory, \\
Oloja Primary Healthcare Center, Nigeria \\
Fasogbon, Samuel Ayobami \\
Quality Assurance Manager, Department of Quality Assurance, \\
Public Health in-Vitro Diagnostics Control Laboratory (Ivds), \\
Medical Laboratory Science Council of Nigeria \\
Ejike, Anthonia \\
Senior Medical Laboratory Scientist, Department of Medical Laboratory, \\
Clina Lancet Laboratories, Nigeria \\
Agbor, Vivian Okemena \\
Clina Lancet Laboratories, Nigeria \\
Ogunjimi, Tolulope Samuel \\
Lead Medical Laboratory Scientist (Microbiogy Unit), Department of Medical Laboratory \\
Lead City University, Ibadan, Nigeria \\
\hline
\end{tabular}

\begin{abstract}
:
Background:Chronic myeloid leukemia (CML) is a clonal myeloproliferative expansion of transformed, primitive hematopoietic progenitor cells. It involves myeloid, monocytic, erythroid, megakaryocytic, B-lymphoid, and occasionally Tlymphoid lineages.

Aim: This research was aimed at detecting the BCR-ABL fusion gene in patients with chronic myeloid leukaemia using reverse transcriptase polymerase chain reaction technique.

Material and Method: Eight adults ( aged 45years and above) blood samples were collected from the clinics of Lautech Teaching Hospital, Osogbo, Osun State, Nigeria and University College Hospital, Ibadan, Oyo State, Nigeria. RNA was extracted and purified from CML blood samples using Axyprep multisource Total RNA miniprep kit, USA procedures were followed.

Result: At the end of the reaction, amplifications were not observed at the annealing temperature of $55{ }^{\circ} \mathrm{C}$. The only bands were the primer sets and some DNA contaminations at the RNA controls for both multiplex and nested PCRs.

Conclusion: Total RNA extraction from the blood sample is crucial to the success of RT-PCR, without this, the study cannot run to completion. Meanwhile, in this experiment, it was observed that there were no bands when the eluted total RNA was run on gel electrophoresis. This indicates that there were no extraction of RNA. Rapid degradation of RNA is the most important factor impeding the analysis of gene expression in human cells and tissues.l
\end{abstract}

Keywords: CML, BCR-ABL, RNA, electrophoresis, RT-PCR

\section{Introduction}

Chronic myeloid leukemia (CML) is a clonal myeloprolifer ative expansion of transformed, primitive hematopoietic progenitor cells. It involves myeloid, monocytic, erythroid, megakaryocytic, B-lymphoid, and occasionally Tlymphoid lineages[1]. Chronic myeloid leukemia was the first human disease in which a specific abnormality of the karyotype - the Philadelphia ( $\mathrm{Ph}$ ) chromosome - could be linked to pathogenetic events of leukemogenesis [2]. It was among the first neoplastic diseases in which therapy which a biologic agent (interferon) was found to suppress the leukemic clone and prolong survival [3]. 
The median age at presentation is 53 years, but all age groups, including children, are affected. Most patients also have thrombocytosis, which is consistent with the presence of a defect in a pluripotent hematopoietic stem cell. The typical symptoms at presentation are fatigue, anorexia, and weight loss, but about 40 percent of patients are asymptomatic, and in these patients, the diagnosis is based solely on an abnormal blood count. The most common abnormality on physical examination is splenomegaly, which is present in up to half of patients. The natural history of chronic myeloid leukemia is progression from a benign chronic phase to a rapidly fatal blast crisis within three to five years. The blast crisis is often preceded by an accelerated phase in which increasing doses of hydroxyurea or busulfan are required to lower the neutrophil count. In contrast to the maturation of chronic myelogenous leukemia cells during the chronic phase, during blast or lymphoblasts found in patients with acute leukemias [4].

The diagnosis of chronic myeloid leukemia is usually based on detection of the Philadelphia $(\mathrm{Ph})$ chromosome. This abnormality, first described as a shortened chromosome 22 in 1960 [2] and then as at (9;22) translocation in 1973 [5], is present in 95 percent of patients. Another 5 percent have complex or variant translocations involving additional chromosomes that have the same end result, which is fusion of the BCR (breakpoint cluster region) gene on chromosome 22 to the ABL (Abelson leukemia virus) gene on chromosome 9. The Philadelphia chromosome is found in cells from the myeloid, erythroid, megakaryocytic, and B-lymphoid lineages, indicating that chronic myeloid leukemia is a stem cell disease [6].

Chronic Myeloid Leukaemia has been the paradigm for the integration of molecular biology with clinical care. In future gene expression array studies will classify the biologic state of disease, and suggest routes of tailored therapy based on the profile or response genes. Chronic myelogenous leukemia (CML) constitutes a clinical model for molecular detection and therapy surveillance of malignant disease since this entity was the first leukemia shown to be associated with a specific chromosomal rearrangement, the Philadelphia $(\mathrm{Ph})$ translocation $\mathrm{t}(9 ; 22)(\mathrm{q} 34 ; \mathrm{q} 11),[2][5][4$ ];which generates two chimeric genes: BCR-ABL[7][8] on the derivative chromosome 22, and ABL-BCR on the derivative chromosome 9. BCR-ABL is transcribed and translated in most patients into a $210 \mathrm{kDa}$ fusion protein with deregulated tyrosine kinase activity. ABL-BCR is expressed in about $60 \%$ of patients with CML, but probably lacks any biological function[9].

After the first discovery of translocation $t(9 ; 22)$ (q34;q11) which is between breakpoint cluster region (BCR) gene on chromosome 22 and ABL gene on chromosome 9, many chromosomal aberrations causing fusion genes in cancer have been shown by cytogenetic techniques[10][11][12]. Discovery of molecular techniques have led to more precise determination of percentage of cases with certain chromosomal aberrations. Translocation $t(9 ; 22)$ is observed in $95 \%$ of CML (chronic myelogenous leukemia) patients, in 2-10\% of pediatric AML (acute myeloid leukemia) cases, and in20-50\% of adult ALL (acute lymphoblastic leukemia) cases In addition, this translocation might be seen in less than2\% of AML cases and rarely seen in lymphoma and myeloma cases. Different transcription products, namely p190, p210, and p230, might arise from different breakpoints on BCR gene [13][14][15].

$\operatorname{Inv}(16)(\mathrm{p} 13 ; \mathrm{q} 22)$ is found in almost all AML-M4Eo subgroup patients. This translocation is formed due to fusion of core binding factor beta (CBFB) gene and myosin heavy chain 11 (MYH11) gene (9). Translocation t (15;17) (q22; q21) is detected in acute promyeloid leukemia (APL) M3 patients which constitute $10 \%$ of all AML cases. In $t(15 ; 17)$ translocation, a chimerical protein is formed by fusion of promyelotic leukemia (PML) gene on 15q22 and retinoic acid receptor alpha (RARA) gene on 17q21. This fusion protein is observed in 98\% of APL cases[16]. Translocation $\mathrm{t}(8 ; 21)(\mathrm{q} 22 ; \mathrm{q} 22)$ is the product of fusion of eight twenty-one (ETO) gene on chromosome 8 and acute myeloid leukemia 1 (AML1) gene on chromosome 21. This translocation is found in 18\% of AML-M2 cases (Miyoshi et al., 1991). Translocation $t(12 ; 21)$ (p13; q22) is formed by fusion of TEL/ ETV6 gene on chromosome 12 and AML1/CBFA2 on chromosome 21 and is observed in $22 \%$ of pediatric ALL cases [17]. Fusion of AF4 gene on chromosome 4 with MLL gene on chromosome 11 causes formation of $\mathrm{t}(4 ; 11)$ ( $\mathrm{q} 21 ; \mathrm{q} 23)$ translocation, which is seen in $50-70 \%$ of infant ALL cases and in approximately $5 \%$ of adult ALL cases [18][13]. Translocation $t(1 ; 19)$ (q23;p13) is formed as a result of fusion of PBX1 gene on chromosome 1 and E2A gene on chromosome 19 and is observed in 3\% of adult ALL cases[19].

The degree of tumor load reduction is an important prognostic factor for patients with CML on therapy[20]. Response is expressed at three levels: (1) hematological response, defined as the normalization of the peripheral blood values and of spleen size; (2) cytogenetic response defined as the proportion of residual Ph-positive metaphases; and (3) molecular response defined according to the method used as the proportion of the residual BCR-ABL gene, transcript, or protein.

Attempts at designing therapeutic tools for CML based on our current knowledge of the molecular and cell biology of the disease have concentrated on 3 main areas-the inhibition of gene expression at the translational level by "antisense" strategies, the stimulation of the immune system's capacity to recognize and destroy leukemic cells, and the modulation of protein function by specific signal transduction inhibitors.

\section{Materials and Methods}

\subsection{Study Sites}

Eight adults ( aged 45years and above) blood samples were collected from the clinics of Lautech Teaching Hospital, Osogbo, Osun State, Nigeria and University College Hospital, Ibadan, Oyo State, Nigeria.

The samples were analyzed at the Molecular Biology Laboratory, Ladoke Akintola University of Technology, Mercyland Wing, Osogbo, Osun State, Nigeria. 


\subsection{Materials}

PCR machine, Axygen RNA kit, water bath, eppendorf tubes, micropipettes, microcentrifuge, primers NB1, AB13, CA3 and B2A, Oven, distilled water, Agerose powder, Boric acid, Taq polymerase, Tris - Borate EDTA buffer, electrophoretic machine, Ultraviolet light and a computer system.

\subsection{RNA Extraction and Purifucation}

RNA was extracted and purified from CML blood samples using Axyprep multisource Total RNA miniprep kit, USA and the following procedures were followed.

Exactly 50 $\mathrm{\mu l}$ of blood sample was added to $400 \mu \mathrm{l}$ of RNA extraction Buffer R-1 and immediately homogenized by vortexing for 5 minutes and the supernatant was discarded. Then 150 $\mathrm{\mu l}$ of Buffer R-11 was added to pellet and vortexed for 30secondsat room temperature. The clarified supernatant was transferredinto a $1.5 \mathrm{ml}$ microfuge tubes provided and $250 \mathrm{\mu l}$ of isopropanol was added and was mixed by vortexing for 30seconds.

A spin/ vac column was placed into a $2 \mathrm{ml}$ microfuge tube, the binding solution of isopropanol was transferred into it and was centrifuged at $6000 \mathrm{xg}$ for 1 minute at room temperature. The filtrate was discarded fromthe spin/vac column and the spin/ vac column was placed back into the same $2 \mathrm{ml}$ microfuge tube then $500 \mu$ of Buffer W1A was added to the spin/vac column and was centrifuge at 12,000xg for 1 minute. Again, the filtrate was discarded and the spin/vac column was placed into another $2 \mathrm{ml}$ microfuge tube and 700 $\mathrm{\mu l}$ of Buffer W2 was added and centrifuged at 12,000xg for 1minute. This process of washing was repeated for the second time with 700 pl of Buffer W2.

The filtrate was discarded from the $2 \mathrm{ml}$ microfuge tube and the spin/vac column was place back into the $2 \mathrm{ml}$ microfuge tube. This is then centrifuged at $12,000 \mathrm{xg}$ for 1 minute to remove residual wash solution. Finally, the spin/vac column was transferred into a clean 1.5ml microfuge tube (provided). 20 $\mathrm{\mu l}$ of Buffer TE (nuclease free) was added to the center of the membrane and was allowed to stand for 1 minute at room temperature and then centrifuged at 12,000xg for 1 minute to elute the total RNA.

\subsection{Removal of DNA using DNA se I}

The DNA was removed with the following preparations:

\section{$10 \mu \mathrm{l}$ of the total RNA extracted}

2pl of BSA

$2 \mu l$ of DNAse I buffer

$2 \mu \mathrm{l}$ of DNAse I

$4 \mu \mathrm{l}$ of PCR water

All these made up $20 \mu \mathrm{l}$ of solution, which was then incubated $37{ }^{\circ} \mathrm{C}$ for 30 minutes and then $65^{\circ} \mathrm{C}$ for 10 minutes.

\section{5.c DNA synthesis (Reverse transcriptase)}

RNA/ primer/ dNTP mix was made by combining the following components in a sterile RNAse - free microfuge tube:

\begin{tabular}{|c|c|}
\hline Total RNA & 3pl \\
\hline Primer dT23VN & $2 \mu \mathrm{l}$ \\
\hline dNTP mix & $4 \mu \mathrm{l}$ \\
\hline nuclease-free water & $9 \mu \mathrm{l}$ \\
\hline Total volume & $16 \mu \mathrm{l}$ \\
\hline
\end{tabular}

The constituted RNA/ primer/ dNTP mix was incubated at $70^{\circ} \mathrm{C}$ for 5 minute, spun briefly and then promptly chilled on ice.

The following components were added to the $16 \mu \mathrm{l}$ RNA/ primer/ dNTP solution and was mixed well by pipetting up and down.

\begin{tabular}{|c|c|c|}
\hline & RT test & RT control \\
\hline 10xRT Buffer & $2 \mu \mathrm{l}$ & $2 \mu \mathrm{l}$ \\
\hline Murine RNAse inhibitor & $0.5 \mu \mathrm{l}$ & $0.5 \mu \mathrm{l}$ \\
\hline m-MuLV reverse transcriptase & $1 \mu \mathrm{l}$ & \\
\hline Nuclease-free water & $0.5 \mu \mathrm{l}$ & $1.5 \mu \mathrm{l}$ \\
\hline Final volume & $2 \mu \mathrm{l}$ & $20 \mu \mathrm{l}$ \\
\hline \multicolumn{2}{|c}{ Table 2} \\
\end{tabular}

The $20 \mu \mathrm{l} \mathrm{cDNA}$ synthesis reaction was incubated at $42^{\circ} \mathrm{C}$ for one hour and enzyme inactivation at $80^{\circ} \mathrm{C}$ for 5 minutes. The reaction volume was brought to $50 \mu \mathrm{l}$ with water and was then stored at $-20^{\circ} \mathrm{C}$. This then ready for PCR amplification. 


\subsection{Preparation for Multiplex PCR}

PCR master mix for four primer sets; c5e, ca3, bcr-c and b2a were prepared in an eppendorf tubes for all cDNA samples to be processed.

\section{C5e 5`ataggaTCCTTTGCAACCGGGTCTGAA3` \\ Ca3 5'TGTTGACTTGGCGTGATGTAGTTGCTTGG $3{ }^{`}$ \\ Bcr-c 5'ACCGCATGTTCCGGGACAAAAG 3` \\ Ba2 5'TTCAGAAGCTTCTCCCTGACAT 3`}

The master mix for these primers contained; $54 \mu \mathrm{l}$ of PCR water, $18 \mu \mathrm{l}$ of c5a, $18 \mu \mathrm{l}$ of ca3, $18 \mu \mathrm{l}$ of bcr-c, $18 \mu \mathrm{l}$ of b2a and $36 \mu \mathrm{l}$ of taq mix. $27 \mu \mathrm{l}$ of the master mix was aliquot onto the $3 \mu \mathrm{l}$ of the cDNA in PCR tubes.

\subsection{Multiplex PCR}

Each PCR experiment was repeated at least once and included a negative and three positive controls. DNA derived from K562 cell line was used as one of the positive controls. Two other positive controls used were from known ALL and CML patients with breakpoints at e1a2 and b2a2 respectively. PCR parameters were 35 cycles at $96{ }^{\circ} \mathrm{C}$ for $1 \mathrm{~min}, 55{ }^{\circ} \mathrm{C}$ for 50seconds, and $72{ }^{\circ} \mathrm{C}$ for $1 \mathrm{~min}$, followed by 10 min extension at $72 \stackrel{\circ}{\circ} \mathrm{C}$. This was carried out a GeneAmp PCR System 9700 by Applied Biosystem.

\subsection{Agarose Gel Electrophoresis}

Electrophoresis was carried out in a 2.0\% agarose slab gels in Tris-borate buffer ( $89 \mathrm{mM}$ Tris, $89 \mathrm{mM}$ boric and EDTA pH 8.0). About $2.0 \mathrm{~g}$ of agarose was weighed into a clean flask and dissolved with $95 \mathrm{ml}$ of distilled water and $5 \mathrm{ml}$ of tris-borate buffer. This was heated on the microwave oven to dissolve the agarose and shaken frequently to prevent charring, and then cooled to $50{ }^{\circ} \mathrm{C} .0 .5 \mu \mathrm{g} / \mathrm{ml}$ of ethidium bromide was then added in order to stain and enable visualization of DNA bands.

A dry Perspex plate $(20 \times 20 \mathrm{~cm})$ was sealed with paper tape to form a mould, the warm agarose was poured into the mould and the comb was well positioned immediately, positioned and clamped in the mould ensuring that there was about $0.5-1.0 \mathrm{~mm}$ of agarose between the bottom of the teeth and the base of the so that sample wells are completely sealed. The gel was allowed to set (20-30 minutes at room temperature), the comb and autoclave tape were removed and mount in the electrophoresis tank and electrophoresis buffer was added to cover the gel. The PCR products were mixed with 10pl of loading buffer, loaded into the slots of the submerged gel using a micropipette and run on the electrophoresis machine at $70 \mathrm{~V}$ for 45 minutes. The 100bp DNA ladder was mixed with $10 \mu \mathrm{l}$ of loading buffer and also loaded on a slot 0 the agarose gel. Sigma Gel Loading Solution Type I was used as the loading buffer. It contains $0.25 \%$ (w/v) Bromophenol blue, $0.25 \%(\mathrm{w} / \mathrm{v})$ Xylene cyanole FF and $40 \%$ (w/v) sucrose in water.

cDNA bands were then visualised and photographed by filtered ultraviolet illumination on the syngene gel documentation system (Syngene, UK). The sizes of DNA product (310, 385, 481 and 808bp) were compared against the $100 \mathrm{bp}$ DNA ladder and the results were obtained.

\section{Results}

At the end of the reaction, amplifications were not observed at the annealing temperature of $55^{\circ} \mathrm{C}$.The only bands were the primer sets and some DNA contaminations at the RNA controls for both multiplex and nested PCRs.

The experiment was tried onStaphyl ococcus aureus as when cultured in the presence of antibiotics, oxacylinin melaitin broth, produces a Methycilline Resistance Staphylococcus aureus gene which is expressed by RNA. After the RNA extraction from the bacteria, RNA gel electrophoresis could not reveal 18s and 22s bands of RNA to confirm successful extraction of total RNA.

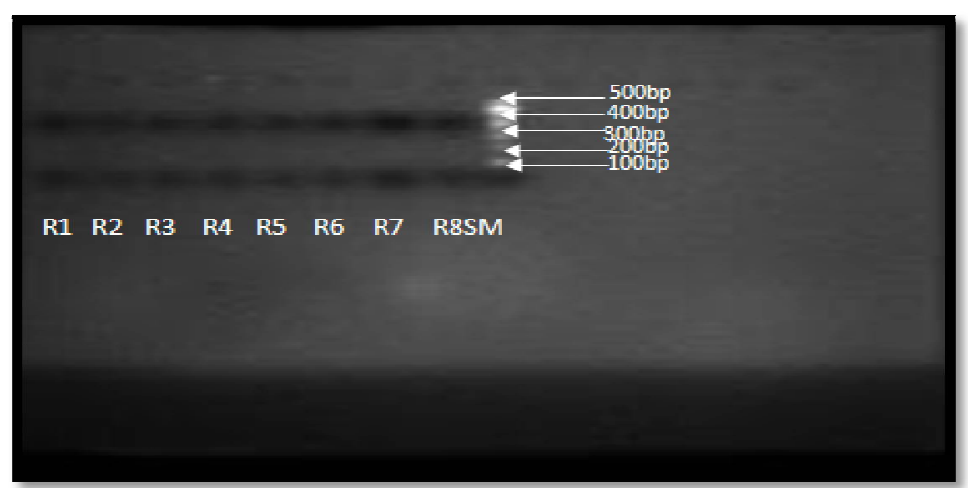

Figure 1: Electrophoretic Gel Showing No Bands after RNA Extraction

Legend: SM: Size Marker, R1 to R8 are sample 1 to 8 respectively. 


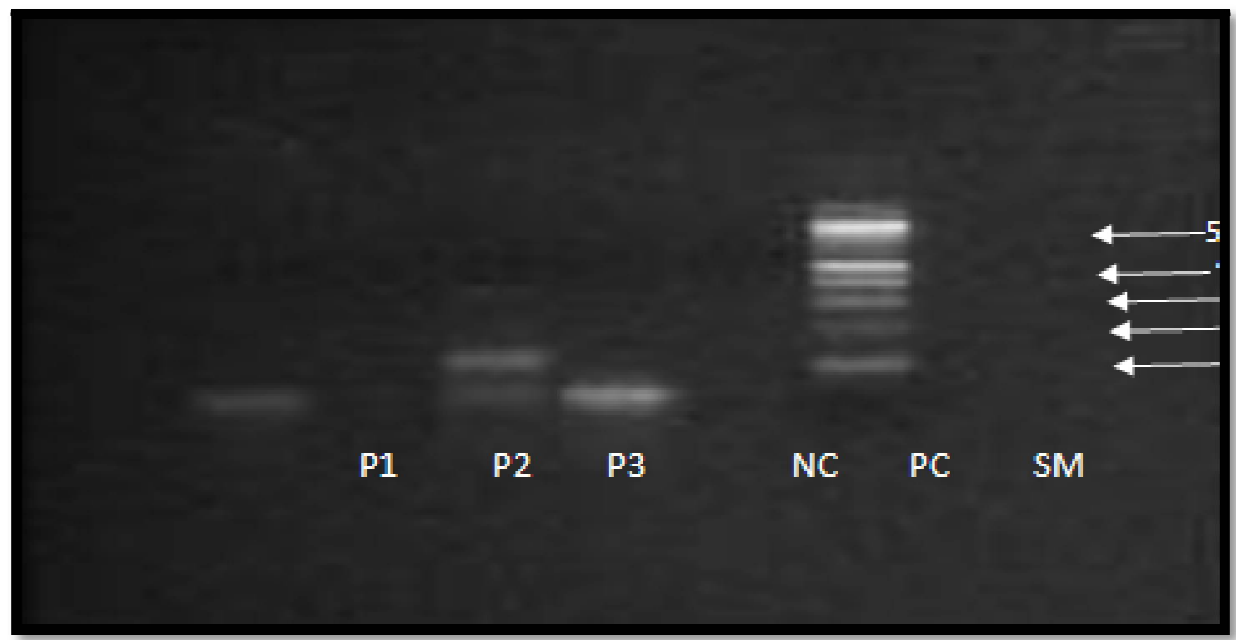

Figure 2: Electro Heretic Gel after Multiplex PCR.P1 a P3 Showed Bands of DNA

Contamination While P2 Revealed No Band

NC Produced Band and PC Revealed No Band

Legend: SM: Size Marker, NC: Negative Control, PC: Positive Control and P1, P2 and P3 are Sample 1, Sample 2 and Sample 3 respectively.

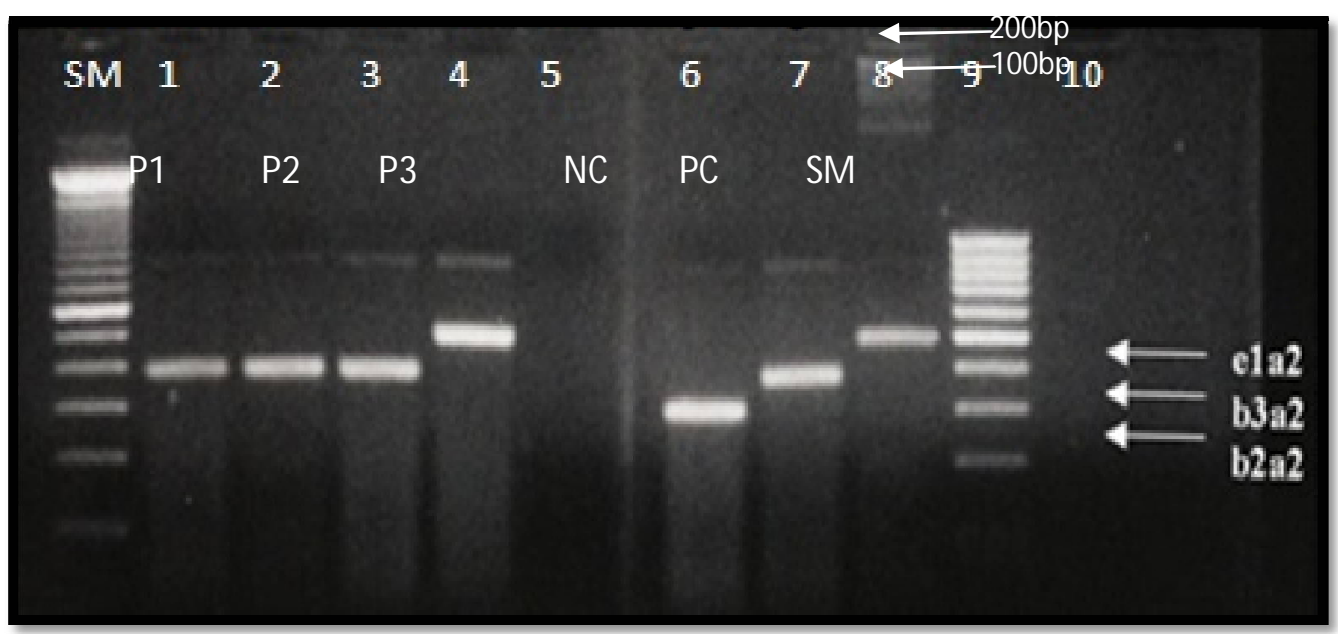

Figure 3: A Standard One-Step Multiplex RT-PCR Results for BCR/ ABL Fusion Transcript

Lane 1, 10: 100bp DNA marker

Lane 2,3,4: 385bp PCR product of b3a2 BCR/ ABL

transcript

Lane 5: 481bp PCR product of e1a2 BCR/ ABL transcript

Lane 6: Negative control

Lane 7,8,9: Positive control for b2a2, b3a2, e1a2

BCR/ ABL transcript respectively

\section{Discussion and Conclusion}

Total RNA extraction from the blood sample is crucial to the success of RT-PCR, without this, the study cannot run to completion. Meanwhile, in this experiment, it was observed that there were no bands when the eluted total RNA was run on gel electrophoresis. This indicates that there were no extraction of RNA.

Rapid degradation of RNA is the most important factor impeding the analysis of gene expression in human cells and tissues. Once a tissue has been removed from its normal environment, the relative rates of RNA synthesis and degradation change. This in turn gave rise to changes in the relative proportions of various RNA species within a tissue, as well as to an overall reduction of RNA concentration. Contamination of samples with exogenous rib nucleases (RNases), particularly those used in the laboratory during RNase treatment of DNA isolates, is universally recognized as an as important cause of RNA loss. The use of meticulous laboratory technique to reduce this contamination absolutely essential to preserve RNA substrates, not sufficient to permit analysis of all RNA target as proven by [21].

It may be due to the potent RNase, eosinophil-derived neurotoxin which is the major factor in reducing the sensitivity of RT-PCR as demonstrated by [22]. [23] also observed in his study that, several endogenous non-secretory RNases complicate the molecular analysis of human tissue. Failure of RNA extraction from method used could be as a 
result of conditions like temperature, prolong time of extraction, centrifugation, vortex time and manufacturer's procedure.

Thus, in this study, environmental factors such as irregular power supply in this parts of the world (southwestern, Nigeria) may have made the extraction procedure for RNA isolation and purification unsuccessful. The insensitivity of Manufacturer's procedure has also contributed to the failure. Therefore, it is highly recommended that this study should serve as a template for developing a quicker, more sensitivity and more reproducible method that will be suitable for this condition than previous RT-PCR based assays for Philadelphia chromosome (bcr/abl translocation) that uses either cell lysate or isolated RNA.

\section{References}

i. Fialkow PJ, Jacobson RJ, Papayannopoulou T. (1977): Chronic myelocytic leukemia: clonal origin in a stem cell common to the granulocyte, erythrocyte, platelet and monocyte/ macrophage. A MJ Med.63:125-30.

ii. Nowell PC, Hungerford DA. (1960): A minute chromosome in human chronic granulocytic leukemia. Science132: 1497-1501,

iii. Talpaz M, Fischer G, Dieckmann K, Hinterberger W, Schneider B, Haas OA, Geissler K, Kalhs P. (1987): Long-term follow-up of patients after related- and unrelated-donor bone marrow transplantation for chronic myelogenous leukemia. Ann Hematol 78: 5070513.

iv. Sawyers CL. (1999): Chronic myeloid leukemia. New EnglJ Med 340: 1330-1340.

v. Rowley JD. (1973): A new consistent chromosome abnormality in chronic myelogenous leukaemia detected by quinacrine fluorescence and Giemsa staining. Nature 243: 290-293.

vi. Bernstein R. (1988): Cytogenetics of chronic myelogenous leukemia. SeninHematol. 20-34.

vii. Groffen J, Stephenson JR, Heisterkamp N, de Klein A, Bartram CR, Grosveld G. (1984): Philadelphia chromosomal breakpoints are clustered within a limited region, bcr, on chromosome 22. Cell 36: 93-99.

viii. Stam K, Heisterkamp N, Grosveld G, de Klein A, Verma RS, Coleman M, Dosik H, Groffen J. (1985): Evidence of a new chimeric bcr/c-abl mRNA in patients with chronic myelocytic leukemia and the Philadelphia chromosome. New Engl J Med 313: 1429-1433.

ix. Melo JV, Gordon DE, Cross NCP, Goldman JM. (1993): The ABL-BCR fusion gene is expressed in chronic myeloid leukemia. Blood 81: 158-165.

x. Hermans A, Heisterkamp N, von Linden M. (1987): Unique fusion of bcr and c-abl genes in Philadelphia chromosome positive acute lymphoblastic leukemia. Cell. 51:33-40.

xi. Rabbits TH. (1994): Chromosomal translocations in human cancer. Nature 372:143-9.

xii. Willis TG, Zalcberg IR, Coignet LJ. (1998): Molecular cloning of translocation t (1;14) (q21; q32) defines a novel gene (BCL9) at chromosome 1q21. Blood 1998; 91:1873-81.

xiii. van Dongen JJM, MacIntyre EA, Gabert JA, Delabesse E. (1999): Rossi V, Saglio G, Gotardi E, Rambaldi A, Dotti G, Giesinger F, Parreira A, Gameiro P, Gonzalez Diaz M, Malec M, Langerak AW, San Miguel JF, Biondi A. Standardized RT-PCR analysis of fusion gene transcripts from chromosome aberrations in acute leukemia for detection of minimal residual disease. Leukemia12: 190101928,

xiv. Barnes DJ, Melo JV. (2002): Cytogenetic and molecular genetic aspects of chronic myeloid leukemia. Acta Haematologica; 108:180-202.

xv. Elia L, Mancini M, Moleti L, (2003): A multiplex reverse transcription-polymerase chain reaction strategy for the diagnostic molecular screening of chimeric genes: a clinical evaluation on 170 patients with acute lymphoblastic leukemia. Hematological 88:275-9.

xvi. Grignani F, Fagioli M, Alcalay M. (1994): Acute promyelocytic leukemia: from genetics to treatment. Blood 83:1025.

xvii. Codrington R, O'Connor HE, Jalali GR, (2000): Analysis of ETV6/AML1 abnormalities in acute lymphoblastic leukemia: incidence, alternative spliced forms and minimal residual disease value. Br J Haematol 111:1071-9.

xviii. Domer PH, Fakharzadeh SS, Chen CS. (1993): Acute mixedlineage leukemia t(4;11)(q21;q23) generates an MLLAF4 fusion product. Proc Natl Acad Sci USA. 90:7884-8.

xix. Melo JV. (1996): The molecular biology of chronic myeloid leukaemia. Leukemia10: 7510756.

xx. Hehlmann R, Heimpel H. (1996): Current aspects of drug therapy in Philadelphia-positive CML: Correlation of

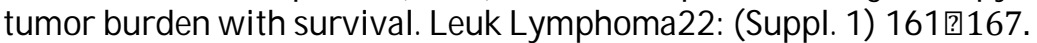

xxi. Bazzoni G, Carlesso N, Griffin JD, Hemler ME. (1996): Bcr/ Abl expression stimulates integrin function in hematopoietic cell lines. J Clin Invest;98:521-528.

xxii. Hämäläinen MM, Eskola JU, Hellman J, Palkki K. (1999): Major interference from leukocytes in reverse transcriptase PCR identified as neutrotoxin ribonuclease from eosinophil detection of residual chronic myelogenous leukaemia from cell lysates by use of an esinophil detected cell preparation. Clin Chem. 45:465-471.

xxiii. Futami J, Tsushima Y, Murato Y, Tada H, Sabaki J, Seno M, Yamada. (1997): Tissue-specific expression of pancreatic-type RNases inhibitor in humans DNA. Cell Biol 16:413-419. 